\title{
Public Health Emergencies, Cancer, and the Legacy of Katrina
}

\author{
Frederick M. Burkle, Jr., MD, MPH, DTM, FAAP, FACEP
}

Senior Fellow and Scientist, Harvard Humanitarian Initiative, Harvard School of Public Health, Cambridge, Massachusetts USA

\section{Correspondence: \\ E-mail: skipmd77@aol.com}

Web publication: 24 August 2007
Public health emergencies denote disasters that adversely impact the public health system and its protective infrastructure. Public health emergencies were first defined in the prototypical complex humanitarian emergencies that dominated the last three decades in developing countries, such as the Sudan, Somalia, Liberia, and Sierra Leone, when unprecedented direct and indirect mortality and morbidity occurred as a consequence of public health protection being destroyed, overwhelmed, not recovered or maintained, or denied to populations for ethnic or religious reasons through political violence, war, or conflict. The consequences primarily focused on limitations of public health infrastructure tied to water, sanitation, shelter, food, and basic health, and its effects on the most vulnerable populations of women, children, the disabled, and the elderly. Emphasis in relief aid is placed on controlling and managing outbreaks of communicable diseases, food shortages leading to under-nutrition and eventual malnutrition, insecurity, population displacement, and loss of livelihoods. In developing countries suffering acute and chronic poverty with life spans in the thirties and forties, chronic diseases are less common and when they exist, often suffer early complications, and demise from lack of resources for diagnosis and treatment. In many respects, chronic diseases remain a luxury not experienced by the poor and dispossessed.

In recent years, complex emergencies have occurred in developed countries such as the former Yugoslavia, and now Iraq where prolonged war subtlety moved established public health systems with good health indices to a status consistent with the worst in the world. Whereas studies focus on worsening infant and under age mortality rates, both Iraq and the former Yugoslavia also suffered when warehoused medications became unavailable and when diagnostic resources for chronic diseases such as diabetes, cardiac disease, and cancer were destroyed. Many died in the process, but for the most part, these deaths have gone uncounted and unnoticed. In the rush to provide some semblance of emergency health provisions, assessments and aid programs rarely address populations with chronic diseases or are included in epidemiological studies that identify and define the most vulnerable of populations.

Recently, political scientists have added new information to our understanding of public health emergencies by measuring the burden of disease from war and conflict using disability adjusted life year. Even after the shooting has stopped, indirect (excess deaths) mortality may continue to increase for as long as several years and may not return to the pre-war baseline for up to a decade due to a lack of recovery and rehabilitation of political governance, economic stability, public safety, and the dependent public health system and its infrastructure. ${ }^{1}$ Though people living in highly-developed countries may think their public health systems are protected from such a rapid decline in post-disaster public health. We now know that similar public health emergencies can occur whenever and wherever the protective public health cover is breached. This was observed following Hurricane Katrina and the Indian Ocean Tsunami. Furthermore, large-scale, naturally occurring epidemics, pandemics, or deliberate biological, chemical, or radiation disasters have the potential to cause widespread and catastrophic public health emergencies.

In 2004, the Centers for Disease Control and Prevention in their assessment of the elderly after Hurricane Charley in Florida noted disruptions in 
the quality of life status and medical care, and excess deaths from preexisting conditions such as cancer. ${ }^{2}$ In this issue of Prebospital and Disaster Medicine, Joseph et al greatly added to the definition and understanding of the consequences of public health emergencies in developed countries where having a chronic disease is commonplace. Indeed, by recognizing the unprecedented public health system damage caused by Katrina's aftermath in 2005, they recommend crucial steps that must be taken to identify and appropriately refer cancer patients, including the unparalleled inclusion of cancer patients in post-disaster surveillance systems. ${ }^{3}$ All large-scale disasters due to natural hazards require a shift from individual-based care to populationbased care, the latter providing estimates of the number of cancer patients potentially displaced, the type of cancer, and the management required. This is required for all chronic diseases. By rapidly re-establishing both individual- and population-based care, a fact of life in an intact public health system, the vulnerability, risk, and excess deaths in this critically vulnerable population will be miti- gated. Unfortunately, in the July 2007 issue of the Disaster Medicine and Public Healtb Preparedness, Stephens et al report a previously unrecognized excess mortality of $47 \%$ two years after Hurricane Katrina. This problem failed to be recognized because of delayed reporting, untimely analysis, and the lack of interoperability between state and local health departments. This was brought about by a poorly recovered public health and surveillance system in the aftermath of the disaster. ${ }^{4}$

These studies signal the disaster medicine community that future studies are required to identify the exact causes of delayed indirect deaths. These studies, along with an inclusive post-disaster surveillance system serve as the first steps in reaching an accurate definition of the consequences of emerging public health emergencies, which are of equal risk in developing and developed countries alike. The concept of public health emergencies, once only the purview of developing countries at war, has become in the semantics of disaster terminology the unifying mantra that the world is indeed flat.

\section{References}

1. Ghobarah HA, Huth P, Russett B: Postwar public health effects of civil conflict. Soc Sci Med 2004;59(4):869-884.

2. Centers for Disease Control and Prevention: Rapid assessment of the needs and health status of oider adults after Hurricane Charley-Charlotte, DeSoto, and Hardee counties, Florida, August 27-31, 2004. MMWR 2004;36:837-840.

3. Joseph DA, Wingo PA, King JB, et at: Use of State cancer surveillance data to estimate the cancer burden in disaster affected areas: Hurricane Katrina, 2005. Prebosp Disast Med 2007;22(4):282-290.

4. Stephens KU, Grew D, Chin K, et al: Excess mortality in the aftermath of Hurricane Katrina: A preliminary report. Disaster Medicine and Public Health Preparedness 2007;1(1):15-20. 